\title{
Impact and predictors of acute exacerbation of interstitial lung diseases after pulmonary resection for lung cancer
}

\author{
Toshihiko Sato, MD, PhD, ${ }^{\text {a }}$ Satoshi Teramukai, $\mathrm{PhD},{ }^{\mathrm{b}}$ Haruhiko Kondo, $\mathrm{MD}, \mathrm{PhD},{ }^{\mathrm{c}}$ Atsushi Watanabe, MD, \\ $\mathrm{PhD},{ }^{\mathrm{d}}$ Masahito Ebina, MD, PhD, ${ }^{\mathrm{e}}$ Kazuma Kishi, MD, PhD, ${ }^{\mathrm{f}}$ Yoshitaka Fujii, MD, PhD, ${ }^{\mathrm{g}}$ \\ Tetsuya Mitsudomi, MD, PhD, ${ }^{\mathrm{h}}$ Masahiro Yoshimura, $\mathrm{MD}, \mathrm{PhD},{ }^{\mathrm{i}}$ Tomohiro Maniwa, MD, \\ Kenji Suzuki, MD, PhD, ${ }^{\mathrm{k}}$ Kazuhiko Kataoka, $\mathrm{MD}, \mathrm{PhD},{ }^{1}$ Yukihiko Sugiyama, $\mathrm{MD}, \mathrm{PhD},{ }^{\mathrm{m}}$ \\ Takashi Kondo, MD, PhD, ${ }^{\mathrm{n}}$ and Hiroshi Date, $\mathrm{MD}, \mathrm{PhD},{ }^{\mathrm{a}}$ for the Japanese Association for Chest Surgery
}

Objective: The study objective was to examine the incidence, risk factors, and mortality rate of acute exacerbation of interstitial lung diseases in patients with lung cancer undergoing pulmonary resection in a large-scale multi-institutional cohort.

Methods: We retrospectively analyzed 1763 patients with non-small cell lung cancer who had undergone pulmonary resection and presented with a clinical diagnosis of interstitial lung diseases between January 2000 and December 2009 at 61 hospitals in Japan. The incidence and outcomes of acute exacerbation within 30 days from the operation were investigated. Univariate and multivariate logistic regression analyses were used to identify independent risk factors of acute exacerbation.

Results: Acute exacerbation occurred in 164 patients $(9.3 \%$; $95 \%$ confidence interval, $8.0-10.8)$, with a mortality rate of $43.9 \%$, and was the top cause of 30-day mortality $(71.7 \%)$. The following 7 independent risk factors of acute exacerbation were identified: surgical procedures, male sex, history of exacerbation, preoperative steroid use, serum sialylated carbohydrate antigen KL-6 levels, usual interstitial pneumonia appearance on computed tomography scan, and reduced percent predicted vital capacity. Surgical procedures showed the strongest association with acute exacerbation (using wedge resection as the reference, lobectomy or segmentectomy: odds ratio, 3.83; 95\% confidence interval, 1.94-7.57; bi-lobectomy or pneumonectomy: odds ratio, 5.70; 95\% confidence interval, 2.38-13.7; $P<.001$ ). The effect of perioperative prophylactics, such as steroids and sivelestat, was not confirmed in this study.

Conclusions: Pulmonary resection for patients with lung cancer with interstitial lung diseases may provoke acute exacerbation at a substantially high rate and has high associated mortality. Surgical procedures that proved to be a risk factor for acute exacerbation should be chosen cautiously for these high-risk patients. (J Thorac Cardiovasc Surg 2014;147:1604-11)

\footnotetext{
From the Department of Thoracic Surgery, ${ }^{\text {a }}$ Kyoto University, Kyoto, Japan; Innova-

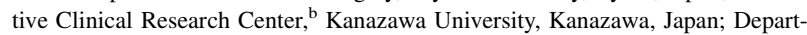
ment of Thoracic Surgery, ${ }^{c}$ Kyorin University School of Medicine, Tokyo, Japan; Department of Thoracic and Cardiovascular Surgery, ${ }^{\mathrm{d}}$ Sapporo Medical University School of Medicine and Hospital, Sapporo, Japan; Department of Respirology, ${ }^{\mathrm{e}}$ Tohoku University, Sendai, Japan; Department of Respiratory Medicine, ${ }^{f}$ Respiratory Center, Toranomon Hospital, Tokyo, Japan; Department of Oncology, ${ }^{\mathrm{g}}$ Immunology and Surgery, Nagoya City University, Nagoya, Japan; Department of Thoracic Surgery, ${ }^{\text {h }}$ Aichi Cancer Center Hospital, Nagoya, Japan (presently at the Department of Thoracic Surgery, Kinki University Faculty of Medicine, Osaka, Japan); Department of Thoracic Surgery, ${ }^{\mathrm{i}}$ Hyogo Cancer Center, Akashi, Japan; Division of Thoracic Surgery, ${ }^{\mathrm{j}}$ Shizuoka Cancer Center, Shizuoka, Japan; Department of General Thoracic Surgery, ${ }^{\mathrm{k}}$ Juntendo University School of Medicine, Tokyo, Japan; Department of Thoracic Surgery, ${ }^{1}$ Hiroshima City Hospital, Hiroshima, Japan (presently at the Department of Thoracic Surgery, Iwakuni Clinical Center, Yamaguchi, Japan); Department of Pulmonary Medicine, ${ }^{\mathrm{m}}$ Jichi Medical University, Tochigi, Japan; and Department of Thoracic Surgery, ${ }^{\mathrm{n}}$ Institute of Development, Aging and Cancer, Tohoku University, Sendai, Japan.

Disclosures: Authors have nothing to disclose with regard to commercial support.

The investigators and institutions participating in this study are listed in Appendix E1.

Received for publication April 4, 2013; revisions received Sept 16, 2013; accepted for publication Sept 25, 2013; available ahead of print Nov 22, 2013.

Address for reprints: Hiroshi Date, MD, PhD, Department of Thoracic Surgery, Kyoto University, Kyoto, Japan (E-mail: hdate@kuhp.kyoto-u.ac.jp). 0022-5223/\$36.00

Copyright (c) 2014 by The American Association for Thoracic Surgery http://dx.doi.org/10.1016/j.jtcvs.2013.09.050
}

丹 Supplemental material is available online.

Interstitial lung diseases (ILDs) are associated with an increased risk of lung cancer. ${ }^{1,2}$ Therapeutic modalities for patients with lung cancer with ILDs should be selected carefully because interventions may provoke exacerbation of ILDs. ${ }^{3,4}$ Pulmonary resection has been shown to be associated with high postoperative morbidity and mortality in these patients. Postoperative acute exacerbation (AE) of interstitial pneumonia is one such possible comorbidity and is associated with mortality rates between $33.3 \%$ and $100 \% .^{5-8}$ In addition to treatmentrelated morbidity and mortality, the prognosis of ILDs itself-particularly in patients with idiopathic pulmonary fibrosis (IPF) — can be a life-limiting factor. Several retrospective studies suggest a median survival time of patients with IPF from 2 to 3 years after diagnosis. ${ }^{9-13}$ Whether 


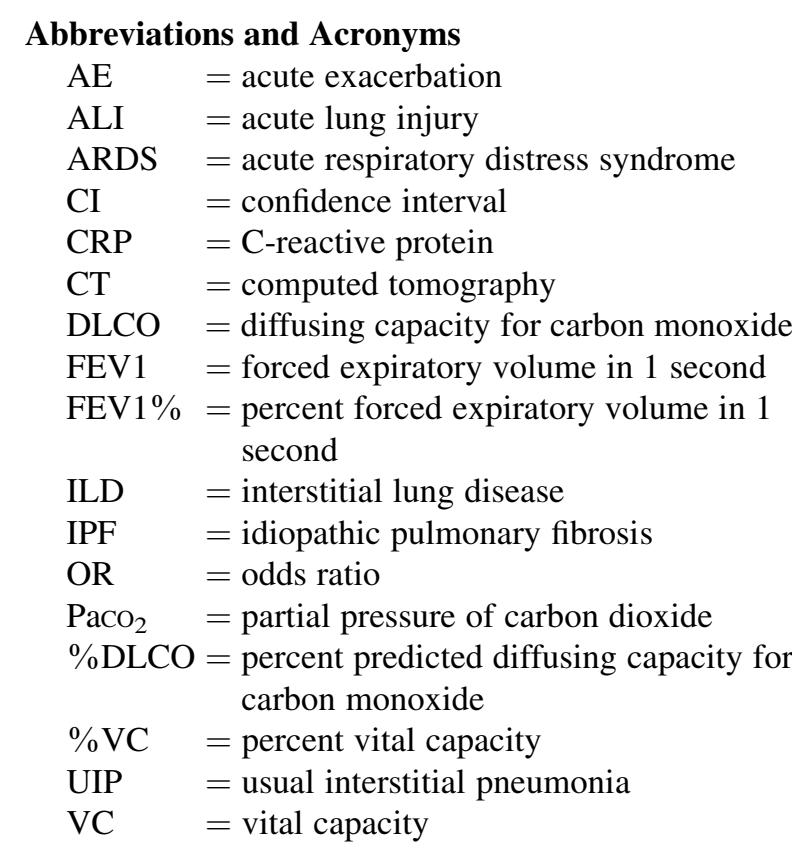

pulmonary resections are indicated for patients with lung cancer with fibrosis remains a matter of debate. , 14-16 $^{-16}$

To determine the most appropriate treatment strategy, a reliable assessment of the risks and benefits of the various interventions is required. However, no cohort study of a sufficiently large scale for this purpose has been conducted. The purpose of this study was therefore to clarify the incidence, risk factors, and outcomes of postoperative AE in patients with lung cancer with ILDs who had undergone pulmonary resection. At the initiative of the Japanese Association for Chest Surgery, we have conducted a large-scale multi-institutional retrospective cohort study to inform the decision-making process for these patients.

\section{MATERIALS AND METHODS}

\section{Study Design and Patients}

The design of the study was planned by Drs Sato, Teramukai, and Date with assistance from the advisory board of the Japanese Association for Chest Surgery and the Project Team for Diffuse Lung Diseases, organized by the Japanese Ministry of Health, Labour and Welfare. The study protocol was approved by the institutional review boards of all participating hospitals, including that of the Ethics Committee, Kyoto University Graduate School and Faculty of Medicine (Approval Number: E-982).

The original data for analysis were obtained from patients with nonsmall cell lung cancer who had undergone pulmonary resection and presented with a clinical diagnosis of ILD between January 2000 and December 2009 at 64 institutions throughout Japan.

The primary end point for outcomes analysis was postoperative AE of interstitial pneumonitis within 30 days after pulmonary resection. Medical records of the patients were reviewed for age; sex; comorbidities, including collagen and respiratory diseases; smoking history; blood work and physiologic data, including white blood cells, C-reactive protein (CRP), lactate dehydrogenase, KL-6 (sialylated carbohydrate antigen KL-6), carcinoembryonic antigen, partial pressure of oxygen, partial pressure of carbon dioxide $\left(\mathrm{PaCO}_{2}\right)$, vital capacity $(\mathrm{VC})$, percent vital capacity $(\% \mathrm{VC})$, forced expiratory volume in 1 second (FEV1), percent FEV1 (FEV1\%), percent predicted FEV1, diffusing capacity for carbon monoxide (DLCO), and percent predicted DLCO (\%DLCO); operation time; bleeding amount; perioperative prophylactics, including steroids, sivelestat sodium hydrate, ulinastatin, and combinations thereof; surgical procedures; tumor location; pathologic diagnosis; and cancer pTNM stages based on the 6th edition of the American Joint Committee on Cancer lung cancer staging.

\section{Inclusion Criteria for Patients With Interstitial Lung Diseases}

Diagnoses of ILDs were confirmed on the basis of a combination of clinical and radiologic findings according to the clinical criteria proposed by the Japanese Respiratory Society, ${ }^{17}$ which are consistent with the guidelines of the American Thoracic Society in $2011 .^{12}$ The cases were categorized into 2 groups according to their radiologic appearance on computed tomography (CT) scan: (1) usual interstitial pneumonia (UIP) pattern: characterized by the presence of basal-dominant reticular opacities and predominantly basal and subpleural distribution of honeycomb lesions, with multiple equal-sized cystic lesions of 2 to $10 \mathrm{~mm}$ diameter with a thick wall; and (2) non-UIP pattern: characterized by the presence of basal-predominant ground glass opacities and infiltrative shadows inconsistent with UIP patterns.

\section{Definition of Postoperative Acute Exacerbation}

$\mathrm{AE}$ caused by pulmonary resection was defined on the basis of criteria proposed by the American Thoracic Society Guidelines ${ }^{12}$ and Yoshimura and colleagues. ${ }^{18}$ These criteria were (1) onset within 30 days after pulmonary resection, (2) intensified dyspnea, (3) increase in the interstitial shadow on chest radiograph and chest CT scan, (4) decrease in arterial oxygen tension of more than $10 \mathrm{~mm} \mathrm{Hg}$ under similar conditions, (5) no evidence of pulmonary infection, and (6) exclusion of alternative causes, such as cardiac failure, pulmonary embolism, or other identifiable causes of lung injury. Exacerbations occurring from 31 days onward were defined as chronic exacerbations.

\section{Patient Characteristics}

Data were initially obtained from 41,742 consecutive patients with lung cancer who had undergone pulmonary resections in 64 institutions; 2418 of these patients presented with ILDs. Because of poor quality of data, 404 cases from 3 institutions were excluded from the study. In addition, 135 cases were excluded because their fibrotic changes were pathologically confirmed, but there were no apparent fibrotic changes detected on CT scans. After reviewing all data for eligibility, completeness, and consistency, 116 more cases were excluded, leaving 1763 cases with ILDs deemed eligible for final analysis in this study.

The demographics of the cohort used in this study are shown in Table 1. The majority of patients were men $(90.4 \%)$ and ex- or current smokers $(93.8 \%)$. History of AE of interstitial pneumonia treated before the index pulmonary resection was observed in $1.1 \%$ of patients. Approximately $6.2 \%$ of patients had been treated preoperatively with steroids and other immunosuppressant drugs, $4.2 \%$ of patients had induction chemotherapy, and $1.8 \%$ of patients had radiation therapy. UIP diagnoses were made in $73.7 \%$ of patients by CT scan, and $45.7 \%$ of patients were confirmed pathologically with resected specimens as having UIP. Squamous cell carcinoma was the most common type of lung cancer.

\section{Statistical Analyses}

Univariate logistic regression analysis was performed to preliminarily evaluate the associations between the incidence of $\mathrm{AE}$ and the following candidate patient characteristics: age, sex, body mass index, smoking history, Brinkman index, comorbidities (asthma, emphysema, and collagen disease), neoadjuvant chemotherapy, neoadjuvant radiation therapy, white blood cells, CRP, lactate dehydrogenase, KL-6, carcinoembryonic antigen, 
TABLE 1. Patient characteristics

\begin{tabular}{|c|c|c|}
\hline Characteristics & $\begin{array}{c}\text { No. of } \\
\text { patients }(\%)\end{array}$ & $\begin{array}{c}\text { Median } \\
\text { (range) }\end{array}$ \\
\hline Age, $y$ & 1763 & $71(36-88)$ \\
\hline \multicolumn{3}{|l|}{ Sex } \\
\hline Male/female & $1593(90.4) / 170(9.6)$ & \\
\hline BMI, $\mathrm{kg} / \mathrm{m}^{2}$ & 1746 & $23.0(13.7-37.0)$ \\
\hline \multicolumn{3}{|l|}{ Smoking history } \\
\hline Never smoker & $109(6.2)$ & \\
\hline Ex-smoker & $1006(57.6)$ & \\
\hline Current smoker & $632(36.2)$ & \\
\hline Brinkman index & 1742 & $1000(0-5760)$ \\
\hline \multicolumn{3}{|l|}{ Comorbidity } \\
\hline \multicolumn{3}{|l|}{ Asthma } \\
\hline$-1+$ & $1724(98.1) / 33(1.9)$ & \\
\hline \multicolumn{3}{|l|}{ Emphysema } \\
\hline$-1+$ & $1167(66.5) / 589(33.5)$ & \\
\hline \multicolumn{3}{|l|}{ Collagen disease } \\
\hline$-1+$ & $1654(94.2) / 102(5.8)$ & \\
\hline \multicolumn{3}{|l|}{ History of $\mathrm{AE}^{*}$} \\
\hline$-1+$ & $1741(98.9) / 20(1.1)$ & \\
\hline \multicolumn{3}{|l|}{$\begin{array}{l}\text { Preoperative } \\
\text { medication } \\
\text { for IP }\end{array}$} \\
\hline $\begin{array}{l}\text { None/steroids/ } \\
\text { others }\end{array}$ & $1638(93.8) / 103(5.9) / 6(0.3)$ & \\
\hline \multicolumn{3}{|l|}{ Neoadjuvant } \\
\hline$-1+$ & $1686(95.8) / 73(4.2)$ & \\
\hline \multicolumn{3}{|l|}{$\begin{array}{l}\text { Neoadjuvant } \\
\text { radiation }\end{array}$} \\
\hline$-1+$ & $1728(98.2) / 32(1.8)$ & \\
\hline \multicolumn{3}{|l|}{ Radiologic } \\
\hline $\begin{array}{l}\text { UIP/non-UIP } \\
\text { pattern }\end{array}$ & $1300(73.7) / 463(26.3)$ & \\
\hline \multicolumn{3}{|l|}{ Histology } \\
\hline $\begin{array}{l}\text { Squamous cell } \\
\text { carcinoma }\end{array}$ & $816(46.9)$ & \\
\hline Adenocarcinoma & $721(41.4)$ & \\
\hline $\begin{array}{l}\text { Large cell } \\
\text { carcinoma }\end{array}$ & $64(3.7)$ & \\
\hline Others & $139(8.0)$ & \\
\hline \multicolumn{3}{|l|}{ pTNM stage } \\
\hline $1 \mathrm{a}$ & 547 (31.6) & \\
\hline $1 b$ & $481(27.8)$ & \\
\hline $2 \mathrm{a}$ & $70(4.0)$ & \\
\hline $2 b$ & $241(13.9)$ & \\
\hline $3 a$ & $244(14.1)$ & \\
\hline $3 b$ & $114(6.6)$ & \\
\hline 4 & $34(2.0)$ & \\
\hline \multicolumn{3}{|l|}{ Surgical procedure } \\
\hline Wedge resection & $275(15.7)$ & \\
\hline Segmentectomy & $150(8.5)$ & \\
\hline Lobectomy & $1236(70.4)$ & \\
\hline Bilobectomy & $61(3.5)$ & \\
\hline Pneumonectomy & $33(1.9)$ & \\
\hline
\end{tabular}

TABLE 1. Continued

\begin{tabular}{lcc}
\hline Characteristics & $\begin{array}{c}\text { No. of } \\
\text { patients }(\%)\end{array}$ & $\begin{array}{c}\text { Median } \\
\text { (range) }\end{array}$ \\
\hline Tumor location & $670(39.2)$ \\
Upper lobe & $77(4.5)$ \\
Middle lobe & $958(56.0)$ \\
Lower lobe & $5(0.3)$ & \\
Multiple & & \\
VATS & $964(54.7) / 798(45.3)$ \\
$-/+$ & \\
Node dissection & $331(17.7) / 339(19.3) / 1104(63.0)$ \\
0/1/2 & The pTNM staging was based on the 6th edition of the American Joint Committee on \\
Cancer lung cancer staging. AE, Acute exacerbation; BMI, body mass index; IP, inter- \\
stitial pneumonia; $U I P$, usual interstitial pneumonia; VATS, video-assisted thoraco- \\
scopic surgery. *History of treated AE before pulmonary resection.
\end{tabular}

partial pressure of oxygen, $\mathrm{PaCO}_{2}, \mathrm{VC}, \% \mathrm{VC}$, FEV1, FEV1\%, \%FEV1, DLCO, \%DLCO, radiologic findings, pathologic findings, history of AE, preoperative steroid use, pTNM stage, operation time, bleeding amount, transfusion, surgical procedures, tumor location, video-assisted thoracoscopic surgery, and node dissection.

Risk factors for inclusion in the multivariate analysis were selected on the basis of the results of the univariate analyses, statistical independence, and clinical significance for preoperative patient evaluation of AE risk.

Surgical procedures were categorized into 3 groups on the basis of the results of multivariate analyses that adjusted for the other covariates. These groups were wedge resection, lobectomy and segmentectomy, and bilobectomy and pneumonectomy. Multivariate logistic regression analysis using backward elimination was used to identify independent risk factors for $\mathrm{AE}$ and to estimate the respective odds ratios (ORs) and their $95 \%$ confidence intervals (CIs) of the various risk factors. All reported $P$ values were 2 -sided. The cutoff value for $\% \mathrm{VC}$ was set at $80 \%$, which is the widely accepted clinical criteria for restrictive change of pulmonary fibrosis, and is correlated to disease progression and patient survival. ${ }^{19}$ For KL-6, $1000 \mathrm{U} / \mathrm{mL}$ was determined as the cutoff value on the basis of the results of a preliminary receiver operating characteristic analysis, which showed $1040 \mathrm{U} / \mathrm{mL}$ to be the optimal cutoff value with a c-index of 0.583 . Data management and statistical analyses were conducted in the Department of Clinical Trial Design and Management, Translational Research Center, Kyoto University Hospital. All statistical analyses were performed using SAS version 9.2 (SAS Institute, Inc, Cary, NC).

\section{RESULTS}

\section{Incidence of Acute Exacerbation}

Postoperative AE developed within 30 days after the operation in approximately $9.3 \%$ of patients $(95 \% \mathrm{CI}$, 8.0-10.8) who had undergone pulmonary resection. AE developed within 10 days after operation in the majority of the patients $(64.6 \%)$, with postoperative day 4 showing the highest frequency of AE. The mortality rate of each postoperative day varied from $0 \%$ to $100 \%$, and showed no particular tendency or trend (Figure 1 and Table 2).

\section{Risk Factor Analysis for Acute Exacerbation}

Univariate and multivariate analyses were carried out to identify possible risk factors for $\mathrm{AE}$. The univariate analysis identified sex, KL-6, $\mathrm{PaCO}_{2}$, \% VC, FEV1.0\%, DLCO, radiologic findings, history of $\mathrm{AE}$, preoperative use of steroids, 


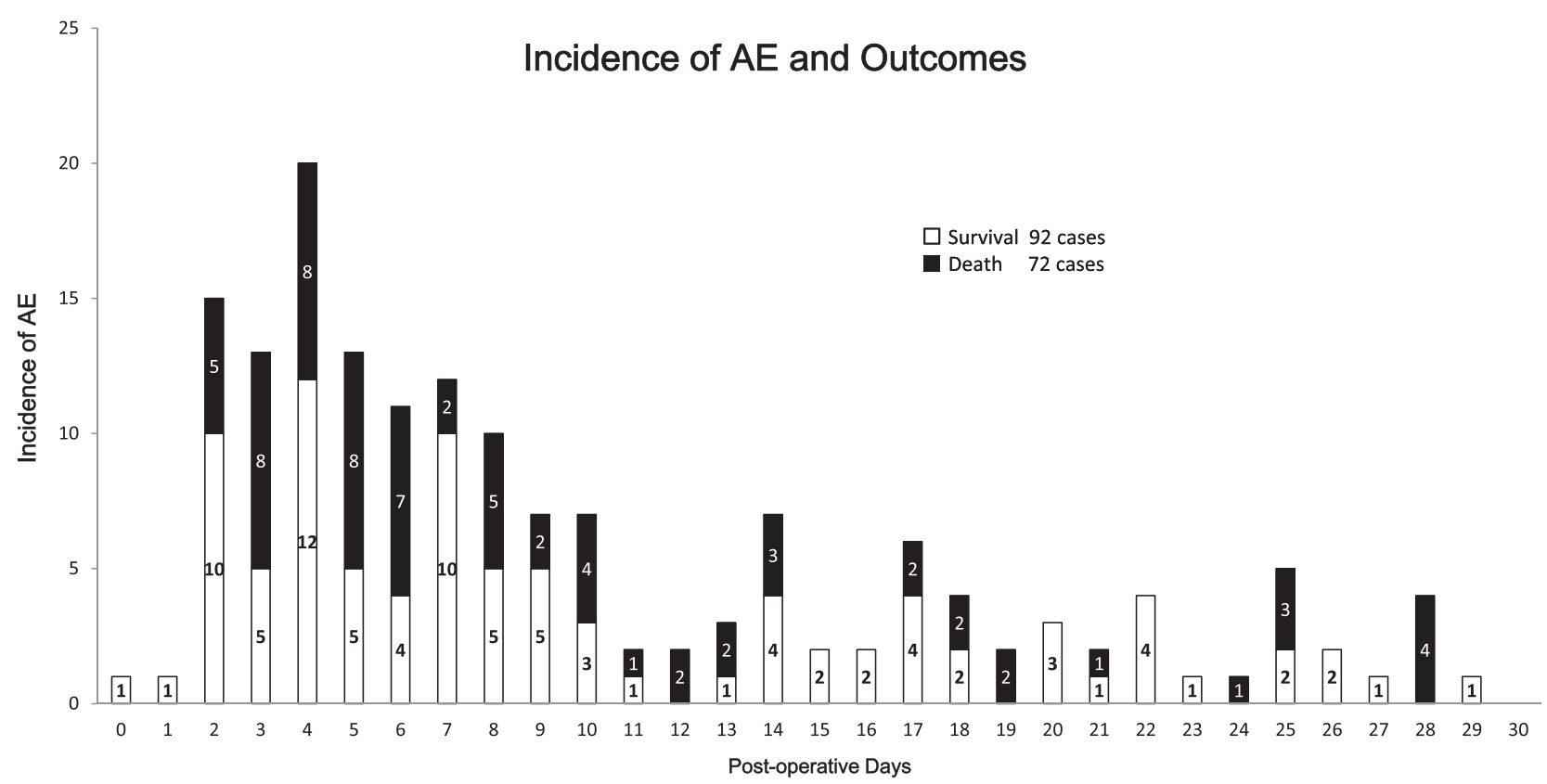

FIGURE 1. Histogram of AE incidence within 30 days after pulmonary resection $(\mathrm{n}=164)$. Black columns represent patient death $(72$ cases, $43.9 \%)$, and white columns represent patient survival $(92$ cases, $56.1 \%)$. AE developed in the majority of the patients $(64.6 \%)$ within 10 days after operation, with postoperative day 4 showing the highest frequency of $\mathrm{AE}$. $A E$, Acute exacerbation.

and surgical procedures as candidate risk factors for $\mathrm{AE}$ (Table E1). VC and FEV1 were excluded as candidates because these variables were highly correlated with $\% \mathrm{VC}$ (Spearman's $r=0.796$ and 0.603 , respectively). Multivariate analysis further identified the following risk factors for AE: sex, KL-6, \% VC, radiologic findings, history of AE, preoperative steroid use, and surgical procedures (Table 3).

The lobectomy/segmentectomy and the bilobectomy/ pneumonectomy groups were both more likely to develop $\mathrm{AE}$ than the wedge resection group, with ORs of 3.83 and 5.70 , respectively. AE was 3 times more likely to develop in male patients than in female patients. Preoperative steroid use, history of AE, UIP pattern on CT scans, elevated levels of KL-6, and reduced \% VC were identified as independent risk factors for AE. Neoadjuvant treatment and video-assisted thoracoscopic surgery showed no association with AE in our study (Table E1).

\section{Surgical Procedures and Acute Exacerbation Risk}

Multivariate analysis of surgical procedures adjusting for KL-6, preoperative steroid use, sex, CT findings, \% VC, and history of $\mathrm{AE}$ was carried out. The associated risk of $\mathrm{AE}$ gradually increased according to resected lung volume. By using the wedge resection group as the referent category, the $\mathrm{OR}$ for $\mathrm{AE}$ in the segmentectomy group was 3.675 (95\% CI, 1.586-8.519; $P=.0024)$; the OR in the lobectomy group was $3.861(95 \% \mathrm{CI}, 1.946-7.660 ; P<.001)$; the OR in the bilobectomy group was 5.055 (95\% CI, 1.871$13.660 ; P=.001)$; and the OR in the pneumonectomy group was $6.953(95 \% \mathrm{CI}, 2.260-21.390 ; P<.001)$.
Risk Factor Analysis for Acute Exacerbation in Patients With Usual Interstitial Pneumonia Patterns on Computed Tomography Scan

Subgroup analyses were carried out for the patients with UIP patterns on CT scans. To ensure only patients with UIP/ IPF were included in this subgroup analysis, we excluded 65 patients with collagen diseases; a total of 1235 cases were analyzed. Sex, CRP, KL-6, \%VC, FEV1, history of

TABLE 2. Incidence of acute exacerbation, its outcomes, and 30-day mortality of patients undergoing pulmonary resection

\begin{tabular}{lcc}
\hline \multicolumn{1}{c}{ Categories } & No. of patients (\%) & Median (range) \\
\hline 30-d mortality & $46(2.6)$ & \\
30-d mortality by cause of death & & \\
AE & $33(71.7)$ \\
Infection & $3(6.5)$ \\
Pulmonary embolism & $1(2.1)$ & \\
Others & $9(19.5)$ & \\
AE & & \\
- & $1599(90.7)$ & \\
+ & $164(9.3)^{*}$ & \\
Days from operation to AE & \\
Outcome of AE & \\
Alive & $92(56.1)$ \\
Death & $72(43.9)$ \\
Days from AE to death & & \\
Side of AE & & \\
Operation side & & \\
Contralateral & & \\
Bilateral & $39(1-82)$ \\
\hline
\end{tabular}

$A E$, Acute exacerbation (occurring within 30 days after pulmonary resection). $* 9.3 \%$; $95 \%$ CI, 8.0-10.8. 
TABLE 3. Results of multivariate logistic regression analyses of acute exacerbation in all patients and in the usual interstitial pneumonia subgroup

\begin{tabular}{|c|c|c|c|c|c|c|c|c|c|c|}
\hline \multirow[b]{2}{*}{ Factors } & \multicolumn{5}{|c|}{ All patients $(n=1763)$} & \multicolumn{5}{|c|}{ UIP subgroup $(\mathbf{n}=1235) *$} \\
\hline & Patients (n) & $\mathbf{A E}(\%)$ & OR & $95 \% \mathrm{CI}$ & $P$ value & Patients (n) & AE $(\%)$ & OR & $95 \% \mathrm{CI}$ & $P$ value \\
\hline Surgical procedures & & & & & $.0005 \dagger$ & & & & & $.0005 \dagger$ \\
\hline Wedge resection & 275 & $10(3.6)$ & 1.000 & - & - & 202 & $10(5.0)$ & 1.000 & - & - \\
\hline Lobectomy/segmentectomy & 1386 & $138(10.0)$ & 3.83 & $1.941-7.567$ & .0001 & 955 & $100(10.5)$ & 2.91 & $1.453-5.847$ & .0026 \\
\hline Bilobectomy/pneumonectomy & 94 & $15(16.0)$ & 5.7 & $2.381-13.66$ & .0001 & 70 & $14(20.0)$ & 5.96 & $2.413-14.74$ & .0001 \\
\hline N/A & 8 & $1(12.5)$ & & & & 8 & $1(12.5)$ & & & \\
\hline \multicolumn{11}{|l|}{ KL-6 (U/mL) } \\
\hline$<1000 \ddagger$ & 834 & $68(8.2)$ & 1.000 & - & - & 571 & $56(9.8)$ & 1.000 & - & - \\
\hline$\geq 1000$ & 209 & $34(16.3)$ & 2.14 & $1.344-3.394$ & .0013 & 151 & $27(17.9)$ & 2.02 & $1.199-3.408$ & .0083 \\
\hline N/A & 720 & $62(8.6)$ & & & & 513 & $42(8.2)$ & & & \\
\hline \multicolumn{11}{|l|}{ Sex } \\
\hline Male & 1593 & $158(9.9)$ & 1.000 & - & - & 1138 & $123(10.8)$ & 1.000 & - & - \\
\hline Female & 170 & $6(3.5)$ & 0.3 & $0.126-0.688$ & .0047 & 97 & $2(2.1)$ & 0.18 & $0.043-0.737$ & .0172 \\
\hline \multicolumn{11}{|l|}{$\% \mathrm{VC}$} \\
\hline$<80$ & 263 & $36(13.7)$ & 1.000 & - & - & 191 & $30(15.7)$ & 1.000 & - & - \\
\hline$\geq 80$ & 1478 & $126(8.5)$ & 0.63 & $0.417-0.959$ & .0308 & 1033 & $94(9.1)$ & 0.57 & $0.350-0.884$ & .0131 \\
\hline N/A & 22 & $2(9.1)$ & & & & 11 & $1(9.1)$ & & & \\
\hline \multicolumn{11}{|l|}{ History of AE } \\
\hline- & 1741 & $158(9.1)$ & 1.000 & - & - & 1223 & $120(9.8)$ & 1.000 & - & - \\
\hline+ & 20 & $6(30.0)$ & 3.24 & $1.063-9.897$ & .0387 & 10 & $5(50.0)$ & 7.67 & $1.997-29.42$ & .0030 \\
\hline N/A & 2 & $0(0.0)$ & & & & 2 & $0(0.0)$ & & & \\
\hline \multicolumn{11}{|l|}{ Preoperative steroid use } \\
\hline - & 1651 & $144(8.7)$ & 1.000 & - & - & & & & & \\
\hline+ & 103 & $20(19.4)$ & 2.46 & $1.356-4.454$ & .0031 & & & & & \\
\hline N/A & 9 & $0(0.0)$ & & & & & & & & \\
\hline \multicolumn{11}{|l|}{ CT findings } \\
\hline UIP pattern & 1300 & $134(10.3)$ & 1.000 & - & - & & & & & \\
\hline Non-UIP pattern & 463 & $30(6.5)$ & 0.59 & $0.386-0.900$ & .0143 & & & & & \\
\hline
\end{tabular}

$A E$, Acute exacerbation; $C I$, confidence interval; $C T$, computed tomography; $N / A$, not available; $O R$, odds ratio; $\% V C$, percent vital capacity; $U I P$, usual interstitial pneumonia. $*$ Cases with collagen diseases were excluded $(\mathrm{n}=65) . \dagger P$ value among 3 surgical procedure categories. $\ddagger$ The cutoff value of $1000 \mathrm{U} / \mathrm{mL}$ was determined on the basis of the result of the receiver operating characteristic analysis.

AE, preoperative steroid use, and surgical procedures were identified as possible risk factors of $\mathrm{AE}$ in the univariate analyses. Multivariate analysis using these factors identified surgical procedures, history of $\mathrm{AE}, \mathrm{KL}-6, \% \mathrm{VC}$, and male sex as independent risk factors (Table 3).

\section{Prophylactics and Acute Exacerbation}

During the perioperative period, $31 \%$ of the patients were administered prophylactics. Steroids were the most common drug for this purpose $(11.4 \%)$, followed by sivelestat $(6.7 \%)$ and a combination of steroid and sivelestat $(5.4 \%)$. The results of multivariate analyses adjusted with the aforementioned $\mathrm{AE}$ risk factors (surgical procedures, sex, KL-6, preoperative steroid use, $\% \mathrm{VC}$, radiologic findings, and history of AE) are shown in Table 4. Drug administration, whether given individually or in combinations, did not show any positive effects in preventing AE.

\section{Morbidity and Mortality of Pulmonary Resection}

Outcomes involving the morbidity and mortality of pulmonary resections are summarized in Table 2 . The 30-day mortality rate was $2.6 \%$, and the most frequent cause of death was $\mathrm{AE}$. In patients with an $\mathrm{AE}$, the mortality rate was $43.9 \%$. Days from $\mathrm{AE}$ to death varied from 1 to 82 days (median, 20 days).

TABLE 4. Use of prophylactics and acute exacerbation

\begin{tabular}{lcccc}
\hline \multicolumn{1}{c}{ Factors } & $\begin{array}{c}\text { No. of } \\
\text { patients (\%) }\end{array}$ & OR & $\mathbf{9 5 \% \text { CI }}$ & $\begin{array}{c}\boldsymbol{P} \\
\text { value }\end{array}$ \\
\hline Prophylactics & & & & \\
- & $1216(69)$ & 1.000 & - & - \\
+ & $544(31)$ & 1.047 & $0.724-1.513$ & .808 \\
Steroid & $194(11.4)$ & 0.862 & $0.491-1.514$ & .605 \\
Sivelestat & $115(6.7)$ & 1.397 & $0.752-2.596$ & .290 \\
Sivelestat + steroid & $92(5.4)$ & 0.749 & $0.338-1.661$ & .477 \\
Ulinastatin & $69(4.0)$ & 2.488 & $1.266-4.887$ & .008 \\
Sivelestat + ulinastatin & $5(0.3)$ & 1.302 & $0.109-15.49$ & .835 \\
Steroid + ulinastatin & $11(0.6)$ & 0.000 & N/A & N/A \\
Sivelestat + steroid + & $4(0.2)$ & 1.035 & $0.089-12.03$ & .978 \\
$\quad$ ulinastatin & & & & \\
\hline Adjusted for surgical procedures, KL-6, preoperative steroid use, sex, CT findings, \% \\
VC, and history of AE. CI, Confidence interval; OR, odds ratio.
\end{tabular}




\section{DISCUSSION}

$\mathrm{AE}$ of interstitial pneumonia is a rapidly progressive disorder often observed in patients with ILDs. Its clinical course is specific and distinguishable from infectious pneumonia. The criteria for identifying AE of pulmonary fibrosis include an unexplained rapid worsening of dyspnea, severely impaired gas exchange, new radiographic diffuse alveolar infiltrates, and the absence of alternate causes, such as infectious pneumonia, pulmonary embolism, pneumothorax, and heart failure. ${ }^{20}$ Thoracic surgery for patients with ILDs, including open lung biopsy and bronchoalveolar lavage, may trigger this decompensating acute respiratory failure. ${ }^{6,21}$ The mortality rate of $\mathrm{AE}$ is reportedly high ${ }^{5-8}$ and has been shown to be the major cause of death for patients with lung cancer after pulmonary resection in a report cumulating more than 10,000 cases from the Japanese Joint Committee for Lung Cancer Registration and in the 2009 annual report of the Japanese Association for Thoracic Surgery. ${ }^{22,23}$ In light of these circumstances, identifying the possible risk factors for $\mathrm{AE}$ and enabling the stratification of patients according to risk are relevant for chest surgeons to reduce operation-related mortality and improve the outcomes of pulmonary resection in patients with lung cancer. To address these issues, we focused on patients with ILDs with lung cancer and found that the incidence of $\mathrm{AE}$ was $0.4 \%$ in patients with non-small cell lung cancer and $9.3 \%$ in similar patients with ILDs; to the best of our knowledge, these are the first such figures reported with high statistical reliability in a large-scale multi-institutional study. These figures were comparable to the incidences documented in past reports, including those of the aforementioned studies, ${ }^{21-26}$ and indicate the difficulties in the treatment of patients with lung cancer with ILDs. The similarities observed in incidences have important implications for further comparisons with other anticancer therapies, such as chemotherapy and radiotherapy, which have been shown to be associated with this fatal complication at the rate of $20 \%$ to $42.9 \%$. $^{3,4}$

We identified 7 risk factors for AE: surgical procedures, elevated KL-6, sex, reduced \% VC, history of AE, preoperative steroid use, and UIP pattern on CT scan. Surgical procedures showed the strongest association with the incidence of AE. Anatomic resection would result in more serious insult to patients' lungs when compared with wedge resection, because the former requires longer operation time and increased hilar vascular procedures and node dissection, which may hinder the lymphatic flow. In addition to damage caused by perioperative patient management (eg, fluid overload, 1-lung ventilation, positive pressure ventilation, and high concentration oxygen exposure), the resection of larger lung volume likely gives greater stress to the endothelium, which may result in AE. Likewise, the effect of a reduced vascular bed is substantial in patients with lower
$\% \mathrm{VC}$ because their residual lung volume is relatively small, which may result in a higher incidence of AE. These speculations are supported by our findings that the risk of $\mathrm{AE}$ gradually increased according to the volume of lung removed (wedge resection $<$ segmentectomy $<$ lobectomy $<$ bilobectomy $<$ pneumonectomy). The less-invasive video-assisted thoracoscopic surgery procedures did not reduce the risk of $\mathrm{AE}$.

The possible effects of blood transfusions on $\mathrm{AE}$ also were considered. We conducted a risk-adjusted evaluation using transfusions and the other 7 covariates, which showed a significant association between transfusion and $\mathrm{AE}$ (OR, 2.04; 95\% CI, 1.22-3.40; $P=.006$ ). However, transfusion also was observed to be highly correlated to the operative procedures, which may bring about possible effects of multicollinearity if included in the same model. Furthermore, the need for transfusions and operation time are to a large degree unpredictable before surgery, which reduces their potential effectiveness for preoperative identification of patients at high risk of developing AE. However, general operation time and the risk of bleeding can be grouped within the types of surgical procedures. The inclusion of surgical procedures in the regression models may therefore adjust for operation time and transfusions.

There are limited data on the value of serum biomarkers in patients with ILDs. Among the clinical laboratory variables, only KL-6 was identified as an independent risk factor for AE, where patients with KL-6 levels more than 1000 IU had an AE incidence twice that of patients with lower levels. KL-6, a circulating glycoprotein expressed from type 2 alveolar pneumocytes and bronchiolar epithelial cells, has been established as an indicator of damage to alveolar cells. ${ }^{27,28}$ Elevated KL-6 levels have been documented in patients who had developed acute lung injury (ALI) or acute respiratory distress syndrome (ARDS), and this relationship may be used to predict patient outcomes. In interstitial pneumonia, KL-6 is an independent factor reflecting the degree of clinical disease activity, confirmed by Ga-citrate scintigraphy and clinical course. ${ }^{27}$ Our observations in which KL-6 was identified as a risk factor have clinical significance because the elevated level of serum KL-6 indicates increased alveolar-capillary permeability, which can lead to diffuse alveolar damage - the initial and essential aspect of AE.

Our results indicated that men had 3 times the risk of developing AE than women. An additional analysis showed that smoking history and the Brinkman index were higher in men than in women; however, the results did not show any significant association between a smoking habit and $\mathrm{AE}$ incidence. Ruffini and colleagues documented that ALI/ ARDS developed in male patients at approximately 4 times the rate of female patients, ${ }^{24}$ so the male lung may be more susceptible to the insult of surgical intervention. 
Although \%DLCO and \% VC have been considered reliable indicators of fibrotic change, ${ }^{12,13,17}$ an analysis of lung function (including FEV1, FEV1\%, \%DLCO, and $\% \mathrm{VC}$ ) showed that only \% VC had a significant and independent association with $\mathrm{AE}$ incidence, which was congruent with the results reported by Kushibe and colleagues $^{29}$ and Shintani and colleagues. ${ }^{30}$

Our analysis showed that preoperative steroid use and history of $\mathrm{AE}$ were independent risk factors for $\mathrm{AE}$, which is consistent with clinical expectations. These findings represent the first time that the statistical associations between these factors have been documented.

The findings in which patients with UIP patterns in CT scans had a higher risk of developing $\mathrm{AE}$ also are consistent with clinical expectations, because honeycomb lesions have been reported to be associated with IPF and act as a prognostic factor. ${ }^{31-33}$ Our own data corroborate this, because patients with distinct honeycomb lesions had a higher risk of developing $\mathrm{AE}$ (OR, 1.800; 95\% CI, 1.157-2.800; $P=.009)$. Further evaluation of the relationship between the extent and the prevalence of honeycomb lesions in CT scans and $\mathrm{AE}$ is required, which we were unable to do in our large retrospective cohort study.

There is no current consensus among the numerous studies regarding the relationship between prophylactic use and postoperative AE. ${ }^{5}$ Prophylactic steroids are a common agent with an anti-inflammatory and stabilizing effect on alveolar cells. However, previous studies with comparatively large cohorts also have revealed no preventive effects from the perioperative administration of steroids. ${ }^{16,25}$ Neutrophil elastase is known to cause endothelial cell injury and increase epithelial permeability, thereby playing an important role in ALI or ARDS. Sivelestat sodium hydrate is a neutrophil elastase inhibitor, and although its clinical efficacy has yet to be clearly demonstrated, ${ }^{34}$ it is widely used for the treatment of ALI in Japan. In our cohort, up to 216 patients $(12 \%)$ had been administered sivelestat in the perioperative period, ostensibly for its prophylactic effects on AE. In our retrospective study, these prophylactics showed no positive effect on $\mathrm{AE}$ prevention. A randomized prospective study on the effects of prophylactics, such as macrolides, $\mathrm{N}$-acetylcysteine, and pirfenidone, is required to gain a clearer understanding of this relationship.

\section{Study Limitations}

This study has several limitations that should be considered in the interpretation of the results. First, this was a retrospective cohort study, which may not necessarily reflect the characteristics of the entire population with this disease entity. Second, the primary inclusion criterion was CT appearance of ILDs. Although radiologic diagnoses were made by each individual institute following criteria based on widely used guidelines, ${ }^{12,17}$ UIP diagnosis may vary among the institutes. We were unable to conduct a centrally controlled review of this aspect of the diagnosis, particularly of the extent and area of honeycomb lesion, which are putative risk factors for the AE.

\section{CONCLUSIONS}

In this study, we have clarified the incidence, risk factors, and outcomes of postoperative AE in patients with lung cancer with ILDs who had undergone pulmonary resection. These results provide essential information for comparisons with other anticancer therapies, such as chemotherapy and radiotherapy. We identified 7 risk factors for $\mathrm{AE}$ onset. By evaluating the presence and degree of the identified risk factors before surgery, we can stratify patients and identify those at high risk for pulmonary resection. Surgical procedures were found to be the strongest risk factor and may represent a crucial step in reducing the incidence of this potentially fatal complication. The findings in this study provide essential information to support fair and objective decision-making by oncologists in the treatment of this difficult entity.

The authors thank Kyosuke Kimura, Asakazu Ogasawara, and Seiko Sakai for laborious efforts in the data management.

\section{References}

1. Hubbard R, Venn A, Lewis S, Britton J. Lung cancer and cryptogenic fibrosing alveolitis. A population-based cohort study. Am J Respir Crit Care Med. 2000; 161:5-8.

2. Harris JM, Johnston ID, Rudd R, Taylor AJ, Cullinan P. Cryptogenic fibrosing alveolitis and lung cancer: the BTS study. Thorax. 2010;65:70-6.

3. Minegishi Y, Takenaka K, Mizutani H, Sudoh J, Noro R, Okano T, et al. Exacerbation of idiopathic interstitial pneumonias associated with lung cancer therapy. Intern Med. 2009;48:665-72.

4. Isobe K, Hata Y, Sakamoto S, Takai Y, Shibuya K, Homma S. Clinical characteristics of acute respiratory deterioration in pulmonary fibrosis associated with lung cancer following anti-cancer therapy. Respirology. 2010;15:88-92.

5. Chiyo M, Sekine Y, Iwata T, Tatsumi K, Yasufuku K, Iyoda A, et al. Impact of interstitial lung disease on surgical morbidity and mortality for lung cancer: analyses of short-term and long-term outcomes. J Thorac Cardiovasc Surg. 2003; 126:1141-6.

6. Kumar P, Goldstraw P, Yamada K, Nicholson AG, Wells AU, Hansell DM, et al. Pulmonary fibrosis and lung cancer: risk and benefit analysis of pulmonary resection. J Thorac Cardiovasc Surg. 2003;125:1321-7.

7. Koizumi K, Hirata T, Hirai K, Mikami I, Okada D, Yamagishi S, et al. Surgical treatment of lung cancer combined with interstitial pneumonia: the effect of surgical approach on postoperative acute exacerbation. Ann Thorac Cardiovasc Surg. 2004;10:340-6.

8. Watanabe A, Kawaharada N, Higami T. Postoperative acute exacerbation of IPF after lung resection for primary lung cancer. Pulm Med. 2011;2011:960316.

9. Bjoraker JA, Ryu JH, Edwin MK, Myers JL, Tazelaar HD, Schroeder DR, et al. Prognostic significance of histopathologic subsets in idiopathic pulmonary fibrosis. Am J Respir Crit Care Med. 1998;157:199-203.

10. Nicholson AG, Colby TV, du Bois RM, Hansell DM, Wells AU. The prognostic significance of the histologic pattern of interstitial pneumonia in patients presenting with the clinical entity of cryptogenic fibrosing alveolitis. Am J Respir Crit Care Med. 2000;162:2213-7.

11. Rudd RM, Prescott RJ, Chalmers JC, Johnston ID. British thoracic society study on cryptogenic fibrosing alveolitis: response to treatment and survival. Thorax. 2007;62:62-6.

12. Raghu G, Collard HR, Egan JJ, Martinez FJ, Behr J, Brown KK, et al. An official ATS/ERS/JRS/ALAT statement: idiopathic pulmonary fibrosis: evidence-based 
guidelines for diagnosis and management. Am J Respir Crit Care Med. 2011;183: 788-824.

13. Ley B, Collard HR, King TE Jr. Clinical course and prediction of survival in idiopathic pulmonary fibrosis. Am J Respir Crit Care Med. 2011;183:431-40.

14. Fujimoto T, Okazaki T, Matsukura T, Hanawa T, Yamashita N, Nishimura K, et al. Operation for lung cancer in patients with idiopathic pulmonary fibrosis: surgical contraindication? Ann Thorac Surg. 2003;76:1674-8.

15. Nakajima J, Takamoto S, Murakawa T, Fukami T, Sano A. Is interstitial pneumonia in patients with collagen diseases a contraindication to lung cancer surgery? Surg Today. 2007;37:14-8.

16. Watanabe A, Higami T, Ohori S, Koyanagi T, Nakashima S, Mawatari T. Is lung cancer resection indicated in patients with idiopathic pulmonary fibrosis? J Thorac Cardiovasc Surg. 2008;136:1357-63, 1363.e1351-2.

17. The Japanese Respiratory Society. Idiopathic Interstitial Pneumonias: Diagnosis and Treatment. 2nd ed. Tokyo, Japan: Nankodo; 2011.

18. Yoshimura K, Nakatani T, Nakamori Y, Chonabayashi N, Tachibana A, Nakata K, et al. [Acute exacerbation in idiopathic interstitial pneumonia]. Nihon Kyobu Shikkan Gakkai Zasshi. 1984;22:1012-20.

19. du Bois RM, Weycker D, Albera C, Bradford WZ, Costabel U, Kartashov A, et al. Ascertainment of individual risk of mortality for patients with idiopathic pulmonary fibrosis. Am J Respir Crit Care Med. 2011;184:459-66.

20. Collard HR, Moore BB, Flaherty KR, Brown KK, Kaner RJ, King TE, et al. Acute exacerbations of idiopathic pulmonary fibrosis. Am J Respir Crit Care Med. 2007; 176:636-43.

21. Utz JP, Ryu JH, Douglas WW, Hartman TE, Tazelaar HD, Myers JL, et al. High short-term mortality following lung biopsy for usual interstitial pneumonia. Eur Respir J. 2001;17:175-9.

22. Sawabata N, Fujii Y, Asamura H, Nomori H, Nakanishi Y, Eguchi K, et al. Lung cancer in Japan: analysis of lung cancer registry cases resected in 2004. Haigan. 2010;50:875-88.

23. Sakata R, Fujii Y, Kuwano H. Thoracic and cardiovascular surgery in Japan during 2008: annual report by the Japanese Association for Thoracic Surgery. Gen Thorac Cardiovasc Surg. 2010;58:356-83.

24. Ruffini E, Parola A, Papalia E, Filosso PL, Mancuso M, Oliaro A, et al. Frequency and mortality of acute lung injury and acute respiratory distress syndrome after pulmonary resection for bronchogenic carcinoma. Eur J Cardiothorac Surg. 2001;20:30-6.

25. Kutlu CA, Williams EA, Evans TW, Pastorino U, Goldstraw P. Acute lung injury and acute respiratory distress syndrome after pulmonary resection. Ann Thorac Surg. 2000;69:376-80.

26. Miyamoto A, Kishi K, Yoshimura K. [A nationwide survey concerning lung surgery for lung cancer associated with idiopathic interstitial pneumonia]. Nihon Kokyuki Gakkai Zasshi. 2011;49:148-50.

27. Kohno N, Kyoizumi S, Awaya Y, Fukuhara H, Yamakido M, Akiyama M. New serum indicator of interstitial pneumonitis activity. Sialylated carbohydrate antigen kl-6. Chest. 1989;96:68-73.

28. Yokoyama A, Kohno N, Hamada H, Sakatani M, Ueda E, Kondo K, et al. Circulating kl-6 predicts the outcome of rapidly progressive idiopathic pulmonary fibrosis. Am J Respir Crit Care Med. 1998;158:1680-4.

29. Kushibe K, Kawaguchi T, Takahama M, Kimura M, Tojo T, Taniguchi S. Operative indications for lung cancer with idiopathic pulmonary fibrosis. J Thorac Cardiovasc Surg. 2007;55:505-8.

30. Shintani Y, Ohta M, Iwasaki T, Ikeda N, Tomita E, Kawahara K, et al. Predictive factors for postoperative acute exacerbation of interstitial pneumonia combined with lung cancer. Gen Thorac Cardiovasc Surg. 2010;58:182-5.

31. Wells AU, Desai SR, Rubens MB, Goh NS, Cramer D, Nicholson AG, et al. Idiopathic pulmonary fibrosis: a composite physiologic index derived from disease extent observed by computed tomography. Am J Respir Crit Care Med. 2003; 167:962-9.

32. Sumikawa H, Johkoh T, Colby TV, Ichikado K, Suga M, Taniguchi H, et al. Computed tomography findings in pathological usual interstitial pneumonia: relationship to survival. Am J Respir Crit Care Med. 2008;177:433-9.

33. Suzuki H, Sekine Y, Yoshida S, Suzuki M, Shibuya K, Yonemori Y, et al. Risk of acute exacerbation of interstitial pneumonia after pulmonary resection for lung cancer in patients with idiopathic pulmonary fibrosis based on preoperative high-resolution computed tomography. Surg Today. 2011;41:914-21.

34. Iwata K, Doi A, Ohji G, Oka H, Oba Y, Takimoto K, et al. Effect of neutrophil elastase inhibitor (sivelestat sodium) in the treatment of acute lung injury (ALI) and acute respiratory distress syndrome (ARDS): a systematic review and meta-analysis. Intern Med. 2010;49:2423-32. 


\section{APPENDIX E1. PARTICIPATING CENTERS AND INVESTIGATORS}

NHO Hokkaido Cancer Center, Hokkaido (H. Adachi); NHO Sendai Medical Center, Miyagi (T. Hasumi); Institute of Development Aging and Cancer Tohoku University, Miyagi (Y. Hoshikawa); Japanese Red Cross Ishinomaki Hospital, Miyagi (S. Suzuki); Ohta Nishinouchi Hospital, Fukushima (Y. Matsumura); Nishi-Niigata Chuo National Hospital, Niigata (T. Watanabe); Niigata University, Niigata (H. Shinohara); Maebashi Red Cross Hospital, Gunma (M. Kamiyoshihara); NHO NishiGunma Hospital, Gunma (O. Kawashima); Dokkyo Medical University, Tochigi (M. Chida); Saitama Cardiovascular and Respiratory Center, Saitama (N. Takahashi); Tokyo Medical University, Tokyo (N. Ikeda); Tokyo Women's Medical University, Tokyo (M. Kanzaki); Tokyo Toranomon Hospital, Tokyo (A. Miyamoto); Juntendo University School of Medicine, Tokyo (T. Matsunaga); Tokyo Metropolitan Cancer and Infectious Disease Center Komagome Hospital, Tokyo (H. Horio); Tokyo Medical and Dental Hospital, Tokyo (K. Okubo); Toho University Omori Medical Center, Tokyo (Y. Hata); The University of Tokyo Graduate School of Medicine, Tokyo (J. Nakajima); Hachioji Medical Center of Tokyo Medical University, Tokyo (H. Miura); Kitasato University School of Medicine, Kanagawa (Y. Satoh); Kimitsu Chuo Hospital, Chiba (T. Iida); Kanagawa Cancer Center, Kanagawa (H. Ito); Fujigaoka Hospital of Showa University, Kanagawa (T. Suzuki); Hamamatsu University School of Medicine, Shizuoka (K. Funai); Seirei Mikatahara General Hospital, Shizuoka (M. Tanahashi); Nagoya University Graduate School of Medicine, Aichi (K. Fukumoto); Aichi Cancer Center Hospital, Aichi (S. Ito); Nagoya Daini Red Cross Hospital, Aichi (H. Yoshioka); Nagoya City University
Graduate School of Medical Sciences, Aichi (M. Yano); Aichi Medical University, Aichi (H. Numanami); Kariya Toyota General Hospital, Aichi (T. Yamada); Graduate School of Medicine, Gifu University, Gifu (H. Iwata); National Mie Chuo Hospital, Mie (K. Adachi); Toyama Prefectural Central Hospital, Toyama (H. Miyazawa); Ishikawa Prefectural Central Hospital, Ishikawa (Y. Tsunezuka); NHO Shiga Hospital, Shiga (S. Inoue); Takatsuki Red Cross Hospital, Osaka (M. Suga); Osaka City University Hospital, Osaka (N. Nishiyama); Osaka University Graduate School of Medicine, Osaka (Y. Shintani); Osaka City General Hospital, Osaka (R. Yamamoto); Osaka Medical Center for Cancer and Cardiovascular Diseases, Osaka (J. Okami); Kishiwada City Hospital, Osaka (M. Kawashima); Wakayama Medical Center Japanese Red Cross Society, Wakayama (S. Sumitomo); Kobe City Medical Center General Hospital, Hyogo (Y. Takahashi); Hyogo Cancer Center, Hyogo (M. Yoshimura); Nishi-Kobe Medical Center, Hyogo (Y. Otake); Tottori University Hospital, Tottori (H. Nakamura); Okayama University Graduate School of Medicine, Okayama (S. Miyoshi); Kurashiki Central Hospital, Okayama (J. Nakano); Kawasaki Medical School, Okayama (M. Nakata); NHO Yamaguchi Ube Medical Center, Yamaguchi (K. Sugi); Kagawa Prefectural Central Hospital, Kagawa (T. Misao); Kochi Health Sciences Center, Kochi (T. Okamoto); NHO Shikoku Cancer Center, Ehime (S. Sawada); Graduate School of Medical Sciences Kyushu University, Fukuoka (T. Yano); Kyushu Cancer Center, Fukuoka (K. Sugio); Kumamoto Chuo Hospital, Kumamoto (T. Saishoji); Nagasaki University Graduate School of Biomedical Sciences Nagasaki (N. Yamasaki); Japanese Red Cross Nagasaki Genbaku Hospital, Nagasaki (I. Sano); Sasebo City General Hospital, Nagasaki (A. Nakamura). 
TABLE E1. Univariable analysis for acute exacerbation

\begin{tabular}{|c|c|c|c|c|c|}
\hline Factors & Categories & Numbers & OR & $\mathbf{9 5} \% \mathrm{CI}$ & $P$ value \\
\hline Age & & 1763 & 1.017 & $0.994-1.041$ & .141 \\
\hline \multicolumn{6}{|l|}{ Sex } \\
\hline & Male & 1593 & 1.000 & - & - \\
\hline & Female & 170 & 0.332 & $0.145-0.763$ & .009 \\
\hline \multicolumn{6}{|l|}{ BMI } \\
\hline & & 1746 & 0.980 & $0.930-1.031$ & .434 \\
\hline \multicolumn{6}{|l|}{ Smoking history } \\
\hline & Never smoker & 109 & 1.000 & - & - \\
\hline & Ex-smoker & 1006 & 1.336 & $0.657-2.720$ & .424 \\
\hline & Current smoker & 632 & 0.893 & $0.424-1.879$ & .765 \\
\hline \multicolumn{6}{|l|}{ Brinkman index } \\
\hline & & 1742 & 1.000 & $1.000-1.000$ & .413 \\
\hline \multicolumn{6}{|l|}{ Comorbidities } \\
\hline \multirow[t]{2}{*}{ Asthma } & - & 1742 & 1.000 & - & - \\
\hline & + & 33 & 0.971 & $0.293-3.217$ & .962 \\
\hline \multirow[t]{2}{*}{ Emphysema } & - & 1167 & 1.000 & - & - \\
\hline & + & 589 & 0.778 & 0.546-1.109 & .165 \\
\hline \multirow[t]{2}{*}{ Collagen disease } & - & 1654 & 1.000 & - & - \\
\hline & + & 102 & 0.936 & $0.463-1.892$ & .854 \\
\hline \multicolumn{6}{|c|}{ Neoadjuvant chemotherapy } \\
\hline & - & 1686 & 1.000 & - & - \\
\hline & + & 73 & 1.207 & $0.569-2.562$ & .624 \\
\hline \multicolumn{6}{|c|}{ Neoadjuvant radiation } \\
\hline & - & 1728 & 1.000 & - & - \\
\hline & + & 32 & 1.401 & $0.485-4.044$ & .533 \\
\hline \multicolumn{6}{|l|}{$\mathrm{WBC}(/ \mu \mathrm{L})$} \\
\hline & & 1737 & 1.000 & $1.000-1.000$ & .111 \\
\hline \multicolumn{6}{|l|}{$\mathrm{CRP}(\mathrm{g} / \mathrm{dL})$} \\
\hline & $<2.0$ & 1462 & 1.000 & - & - \\
\hline & $>2.0$ & 231 & 1.425 & $0.923-2.201$ & .110 \\
\hline \multicolumn{6}{|l|}{ LDH (IU/L) } \\
\hline & & 1730 & 1.002 & $1.000-1.004$ & .064 \\
\hline \multicolumn{6}{|l|}{ KL-6 (U/mL) } \\
\hline & $<1000$ & 834 & 1.000 & - & - \\
\hline & $>1000$ & 209 & 2.189 & $1.405-3.409$ & $<.001$ \\
\hline \multicolumn{6}{|l|}{ CEA (ng/mL) } \\
\hline & & 1664 & 1.000 & $0.997-1.004$ & .883 \\
\hline \multicolumn{6}{|l|}{$\mathrm{PaO}_{2}$ (torr) } \\
\hline & & 1552 & 0.996 & $0.981-1.011$ & 609 \\
\hline \multicolumn{6}{|l|}{$\mathrm{PaCO}_{2}$ (torr) } \\
\hline & & 1547 & 0.954 & $0.914-0.995$ & .030 \\
\hline \multicolumn{6}{|l|}{$\mathrm{VC}(\mathrm{L})$} \\
\hline & & 1750 & 0.566 & $0.441-0.728$ & $<.001$ \\
\hline$\% \mathrm{VC}$ & & & & & \\
\hline & $<80$ & 263 & 1.000 & - & - \\
\hline & $>80$ & 1478 & 0.588 & $0.395-0.873$ & .009 \\
\hline FEV1 (L) & & & & & \\
\hline & & 1748 & 0.683 & $0.496-0.941$ & .020 \\
\hline FEV $1 \%$ & & & & & \\
\hline & $<70$ & 460 & 1.000 & - & - \\
\hline & $>70$ & 1289 & 1.500 & $1.003-2.243$ & .048 \\
\hline$\%$ FEV 1 & & & & & \\
\hline & & 1742 & 0.995 & $0.987-1.002$ & .176 \\
\hline $\mathrm{DLCO}(\mathrm{mL} / \mathrm{min} / \mathrm{to}$ & & & & & \\
\hline & & 1121 & 0.957 & 0.916-0.999 & .047 \\
\hline
\end{tabular}


TABLE E1. Continued

\begin{tabular}{|c|c|c|c|c|c|}
\hline Factors & Categories & Numbers & OR & 95\% CI & $P$ value \\
\hline \multicolumn{6}{|l|}{$\% \mathrm{DLCO}$} \\
\hline & & 1128 & 0.997 & $0.989-1.006$ & .532 \\
\hline \multicolumn{6}{|l|}{ Radiologic findings } \\
\hline & UIP pattern & 1300 & 1.000 & - & - \\
\hline & Non-UIP pattern & 463 & 0.603 & $0.400-0.909$ & .016 \\
\hline \multicolumn{6}{|l|}{ Pathologic findings } \\
\hline & UIP pattern & 709 & 1.000 & - & - \\
\hline & Non-UIP pattern & 418 & 0.904 & $0.608-1.343$ & .616 \\
\hline & No IP diagnosis & 426 & 0.635 & $0.411-0.981$ & .041 \\
\hline \multicolumn{6}{|l|}{ History of AE } \\
\hline & - & 1741 & 1.000 & - & - \\
\hline & + & 20 & 4.295 & $1.628-11.33$ & .003 \\
\hline \multicolumn{6}{|c|}{ Preoperative steroid use } \\
\hline & - & 1651 & 1.000 & - & - \\
\hline & + & 103 & 2.522 & $1.504-4.231$ & $<.001$ \\
\hline \multicolumn{6}{|l|}{ pTNM stage } \\
\hline & $1 \mathrm{a}$ & 547 & 1.000 & - & - \\
\hline & $1 b$ & 481 & 1.349 & $0.858-2.120$ & .195 \\
\hline & $2 \mathrm{a}$ & 70 & 1.488 & $0.638-3.474$ & .358 \\
\hline & $2 b$ & 241 & 1.832 & $1.101-3.049$ & .020 \\
\hline & $3 a$ & 244 & 2.022 & $1.230-3.323$ & .006 \\
\hline & $3 b$ & 114 & 1.011 & $0.459-2.229$ & .979 \\
\hline & 4 & 34 & 2.309 & $0.846-6.307$ & .103 \\
\hline \multicolumn{6}{|c|}{ Operation time (min) } \\
\hline & & 1753 & 1.003 & $1.002-1.005$ & $<.001$ \\
\hline \multicolumn{6}{|l|}{ Bleeding (mL) } \\
\hline & & 1744 & 1.001 & $1.000-1.001$ & $<.001$ \\
\hline \multicolumn{6}{|l|}{ Transfusion } \\
\hline & - & 1629 & 1.000 & - & - \\
\hline & + & 124 & 2.276 & $1.392-3.723$ & .001 \\
\hline \multicolumn{6}{|l|}{ Surgical procedures } \\
\hline & Wedge Resection & 275 & 1.000 & - & - \\
\hline & Segmentectomy/lobectomy & 1386 & 2.930 & $1.521-5.644$ & .001 \\
\hline & Bilobectomy/pneumonectomy & 94 & 5.032 & $2.175-11.64$ & $<.001$ \\
\hline \multicolumn{6}{|l|}{ Tumor location } \\
\hline & Upper lobe & 670 & 1.000 & - & - \\
\hline & Middle lobe & 77 & 0.963 & $0.445-2.083$ & .924 \\
\hline & Lower lobe & 958 & 0.705 & $0.502-0.991$ & .044 \\
\hline & Multiple & 5 & 0.000 & N/A & \\
\hline \multicolumn{6}{|l|}{ VATS } \\
\hline & - & 964 & 1.000 & - & - \\
\hline & + & 798 & 1.199 & $0.869-1.654$ & .268 \\
\hline \multicolumn{6}{|l|}{ Node dissection } \\
\hline & 0 & 311 & 1.000 & - & - \\
\hline & 1 & 339 & 2.979 & $1.559-5.694$ & .001 \\
\hline & 2 & 1104 & 2.587 & $1.436-4.661$ & .002 \\
\hline
\end{tabular}

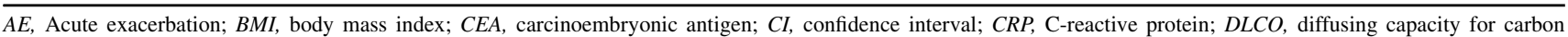
monoxide; FEVl, forced expiratory volume in 1 second; $I P$, interstitial pneumonia; $L D H$, lactate dehydrogenase; $O R$, odds ratio; $P a \mathrm{CO}_{2}$, partial pressure of carbon dioxide; $\mathrm{Pao}_{2}$, partial pressure of oxygen; UIP, usual interstitial pneumonia; VATS, video-assisted thoracic surgery; $V C$, vital capacity; $W B C$, white blood cell; \%VC, percent vital capacity; $F E V 1 \%$, percent forced expiratory volume in 1 second; $\% D L C O$, percent predicted diffusing capacity for carbon monoxide. 